\title{
Type I collagen inhibits differentiation and promotes a stem cell-like phenotype in human colorectal carcinoma cells
}

\author{
SC Kirkland ${ }^{*, 1}$ \\ 'Department of Histopathology, Imperial College London, DuCane Road, London WI 2 ONN, UK
}

BACKGROUND: Human colorectal cancer is caused by mutations and is thought to be maintained by a population of cancer stem cells. Further phenotypic changes occurring at the invasive edge suggest that colon cancer cells are also regulated by their microenvironment. Type I collagen, a promoter of the malignant phenotype in pancreatic carcinoma cells, is highly expressed at the invasive front of human colorectal cancer.

METHODS: This study investigates the role of type I collagen in specifying the colorectal cancer cell phenotype. The effect of type I collagen on morphology, localisation of cell-cell adhesion proteins, differentiation and stem cell-like characteristics was examined in a panel of human colorectal carcinoma cell lines.

RESULTS: Human colorectal carcinoma cells grown on type I collagen in serum-free medium show an epithelial-mesenchymal-like transition (EMT-like), assuming a more flattened less cohesive morphology. Type I collagen downregulates E-cadherin and $\beta$-catenin at cell-cell junctions. Furthermore, type I collagen inhibits differentiation, increases clonogenicity and promotes expression of stem cell markers CDI33 and Bmil. Type I collagen effects were partially abrogated by a function-blocking antibody to $\alpha 2$ integrin.

CONCLUSION: Together, these results indicate that type I collagen promotes expression of a stem cell-like phenotype in human colorectal cancer cells likely through $\alpha 2 \beta$ I integrin.

British Journal of Cancer (2009) I 0I, 320-326. doi:10.1038/sj.bjc.6605/43 www.bjcancer.com

Published online 30 June 2009

(C) 2009 Cancer Research UK

Keywords: colorectal cancer; cancer stem cell; integrin; epithelial-mesenchymal transition; collagen; CD49b

The human colorectal epithelium is maintained by a population of multipotent adult stem cells that self-renew and execute a multilineage differentiation programme yielding absorptive, mucous and endocrine cells (Brittan and Wright, 2004). Human colorectal carcinomas are heterogeneous and contain differentiated cells (Ho et al, 1989), suggesting that cancer stem cells, with a residual capability for multilineage differentiation, propagate colorectal cancer. This concept is supported by the finding that single-cell-derived populations of human colorectal cancer cells have been shown to be both tumourigenic and capable of multilineage differentiation (Kirkland, 1988; Vermeulen et al, 2008). Furthermore, several recent studies have isolated a subpopulation of cancer stem or tumour-initiating cells from human colorectal cancers, which are functionally characterised by their ability to seed new tumours (Dalerba et al, 2007; O'Brien et al, 2007; Ricci-Vitiani et al, 2007).

Epithelial-mesenchymal transition (EMT) has long been implicated in cancer progression (Thiery and Sleeman, 2006), although EMT-like would more accurately describe the changes seen in most cancers where a full transcriptional reprogramming to a mesenchymal phenotype is rarely observed (Klymkowsky and Savagner, 2009). In human colon cancer, EMT-like changes are observed in cells at the invasive edge, but these appear to be reversible as disseminated cells recapitulate the morphology of the primary tumour (Brabletz et al, 2005). Interestingly, EMT-like

*Correspondence: Dr SC Kirkland;

E-mail: s.kirkland@imperial.ac.uk

Received 18 March 2009; revised 22 May 2009; accepted 29 May 2009; published online 30 June 2009 phenotypic changes have recently been linked with stemness in mammary epithelial cells (Mani et al, 2008) and the concept of migratory cancer stem cells has been suggested (Brabletz et al, 2005) to describe human colon cancer progression.

The majority of human colon cancers carry mutations that lead to the activation of Wnt signalling, a pathway that also has a pivotal role in normal intestinal stem cell biology (Reya and Clevers, 2005). Despite the underlying genetic background, cells within individual tumours display differential Wnt signalling, suggesting further regulation by the microenvironment. A local loss of basement membrane at the invasive edge has been suggested to expose cancer cells to a different microenvironment, which promotes Wnt signalling (nuclear $\beta$-catenin expression), EMT-like changes and loss of differentiation (Spaderna et al, 2006). Type I collagen is a known component of the microenvironment at the host-tumour interface in human colorectal cancer (Brabletz et al, 2004) and is more highly expressed in tumours displaying infiltrative growth compared with those with expansive growth (Oku et al, 2008).Type I collagen also reduces cdx-2 expression in human colorectal cancer cell lines in vitro (Brabletz et $a l, 2004)$ and enhances tumourigenicity in human colorectal cancer cells in xenografts (Del-Buono et al, 1991). Furthermore, type I collagen promotes a malignant phenotype in pancreatic cancer through $\alpha 2 \beta 1$ integrin (Grzesiak and Bouvet, 2006) and forms part of a 17-gene signature associated with metastasis (Ramaswamy et al, 2003).

Recently, the collagen receptor $\alpha 2 \beta 1$ integrin has been shown to regulate stem cell fate in multipotent human colorectal cancer cells (Kirkland and Ying, 2008), suggesting that collagen is involved in the loss of differentiation observed at the invasive front. This study 
investigates the effect of type I collagen on the phenotype of human colorectal carcinoma cells.

\section{MATERIALS AND METHODS}

\section{Cells}

Three human colorectal cell lines were used in this study: HCA-7 Colony 29 (Marsh et al, 1993) termed Colony 29 in this study, Caco-2 (ECACC) and a twice cloned population of HRA-19 cells (Kirkland, 1988), which have been subjected to multiplex PCR analysis (ECACC; Porton Down, Salisbury, UK) to confirm their unique profile. Cell lines were grown in Dulbecco's Eagle's medium (Invitrogen, Paisley, UK) supplemented with $10 \%$ foetal bovine serum (FBS) in $7.5 \% \mathrm{CO}_{2}$.

For experiments, cells were transferred to different serum-free media, which are as follows:

\section{IT: DMEM with $2 \mathrm{mM}$ glutamine and $1: 100$ of ITS-X supplement} (Invitrogen)

ITA: IT medium with $10 \mu \mathrm{g} \mathrm{ml}^{-1}$ ascorbic acid

TS: DMEM with $2 \mathrm{mM}$ glutamine, $10 \mu \mathrm{g} \mathrm{ml}^{-1}$ transferrin (Invitrogen) and $5 \mathrm{ng} \mathrm{ml}^{-1}$ selenous acid (Sigma, Gillingham, UK).

\section{Endocrine lineage commitment assay}

Lineage commitment experiments were performed as previously described (Kirkland and Henderson, 2001) or with minor modifications.

\section{Western blotting}

Lysates were prepared with non-reducing SDS lysis buffer (New England Biolabs, Hitchin, UK). Equal amounts of protein (RC-DC assay; Bio-Rad, Hemel Hempstead, UK) were separated on $3-8 \%$ Tris-acetate gels (Invitrogen) and blotted onto nitrocellulose. Blots were stained with Ponceau S solution (Sigma) to check for equal loading. Blots were blocked with $5 \%$ block solution (GE Healthcare, Little Chalfont, UK), rinsed in wash buffer $(10 \mathrm{mM}$ Tris- $\mathrm{HCl}, 0.1 \mathrm{M} \mathrm{NaCl}, 0.1 \%$ Tween 20 ) and incubated overnight with antibodies in the blot wash. Blots were washed and incubated in horseradish peroxidase (HRP)-linked rabbit anti-mouse antibodies (Dako, Ely, UK) in blot wash for $1 \mathrm{~h}$ at room temperature, washed and developed using ECL Plus (GE Healthcare).

\section{Alkaline phosphatase assay}

Subconfluent cells were removed from flasks with trypsin/EDTA solution and added to 10\% FBS in DMEM. Cells were washed twice in DMEM and seeded in serum-free medium comprising Dulbecco's Eagle's medium containing transferrin $\left(10 \mu \mathrm{g} \mathrm{ml}^{-1}\right)$, selenous acid ( $5 \mathrm{ng} \mathrm{ml}^{-1}$ ) and $2 \mathrm{~mm}$ glutamine (TS medium). Cells were plated at $0.6 \times 10^{4}$ cells per well (Caco-2), $1.5 \times 10^{4}$ cells per well (Colony 29) or a 1:5 split ratio (HRA-19). Cells were seeded into collagen-coated 96-well plates (BioCoat; BD Biosciences, Oxford, UK) or equivalent non-coated plates from BD Biosciences (Biocoat plates are coated with $40-60 \mu \mathrm{g} \mathrm{ml}^{-1}$ rat tail collagen: manufacturer information). Occasional experiments were performed using plates coated overnight at $4{ }^{\circ} \mathrm{C}$ with type I collagen (Sigma) $\left(10 \mu \mathrm{g} \mathrm{ml}^{-1}\right)$. After $72 \mathrm{~h}$ at $37^{\circ} \mathrm{C}$, alkaline phosphatase activity was measured using $p$-nitrophenyl phosphate (Millipore, Watford, UK); the reaction product $p$-nitrophenol was measured at $405 \mathrm{~nm}$. Cell numbers were determined in replicate wells using WST-1 reagent (Roche, Burgess Hill, UK) as described by the manufacturer. Alkaline phosphatase absorbance values were normalised using these WST-1 values.

\section{Cell-based enzyme-linked immunosorbent assay}

Quantitative analysis of differentiation and stem cell markers was performed using a cell-based enzyme-linked immunosorbent assay (ELISA) on whole cells in 96-well plates broadly as described previously (Versteeg et al, 2000). Briefly, equal numbers of cells were seeded onto either collagen-coated 96-well plates (Biocoat; BD Biosciences) or control non-coated plates (BD Biosciences). Cells were seeded as follows: HRA-19 (1:5 split ratio) (a single-cell suspension could not be obtained for cell counting): Colony 29 $\left(1.5 \times 10^{4}\right.$ per well $)$ and Caco- $2\left(0.66 \times 10^{4}\right.$ per well $)$ in the medium as indicated. Cells were grown for the times indicated and then fixed in ethanol for intestinal alkaline phosphatase expression or $2 \%$ paraformaldehyde for CD133 and Bmil expression. Cells for Bmi1 measurements were further treated with ice-cold methanol for $20 \mathrm{~min}$.

Cells were washed three times with phosphate-buffered saline (PBS) and endogenous peroxidase blocked with $0.3 \% \mathrm{H}_{2} \mathrm{O}_{2}$ in $\mathrm{PBS}$ for $30 \mathrm{~min}$ at room temperature. Cells were then blocked in $10 \%$ normal serum (species of secondary antibody), drained without washing and incubated with primary antibody for $3 \mathrm{~h}$ at room temperature or overnight at $4{ }^{\circ} \mathrm{C}$ (CD133 (Abcam, Cambridge, UK):Bmil (New England Biolabs):Intestinal Alkaline Phosphatase $($ Abcam)). Wells were washed three times with PBS and then incubated with HRP-conjugated secondary antibody for $1 \mathrm{~h}$ at room temperature. Finally, wells were washed three times in PBS and once in distilled water and then HRP developed with tetramethylbenzidine (Sigma), reaction stopped with $\mathrm{H}_{2} \mathrm{SO}_{4}$ and absorbance read at $450 \mathrm{~nm}$ (620 nm reference). Background levels, in the presence of isotype control antibodies at the same concentration, were deducted from test values. Values were normalised for cell number measured in replicate wells using Cyquant cell proliferation assay (Invitrogen) as indicated by the manufacturer.

To assess the role of $\alpha 2 \beta 1$ integrin in mediating the effects of collagen, some experiments were performed in the presence of $\mathrm{MAb} \mathrm{Ak7}$, a function-blocking antibody to $\alpha 2$ integrin (Gamble et al, 1993).

\section{Immunofluorescence}

Immunofluorescence was performed in eight-chamber slides (Nunc, VWR, Lutterworth, UK). Chambers were coated with type I collagen $\left(50 \mu \mathrm{g} \mathrm{ml}^{-1}\right.$ in $10 \mathrm{~mm}$ acetic acid) (Sigma) overnight at $4{ }^{\circ} \mathrm{C}$. Control wells were incubated with $10 \mathrm{~mm}$ acetic acid. Solutions were removed and wells dried for $2 \mathrm{~h}$ before use. Cells were grown in serum-free medium (TS)-DMEM with $2 \mathrm{~mm}$ glutamine, transferrin $\left(10 \mu \mathrm{g} \mathrm{ml}^{-1}\right)$ and selenous acid $\left(5 \mathrm{ng} \mathrm{ml}^{-1}\right)$ for $72 \mathrm{~h}$ in eight-chamber slides (Nunc).

Cells were fixed in $2 \%$ paraformaldehyde followed by methanol to facilitate antibody access to intracellular antigens. Cells were blocked with $10 \%$ normal serum (species of secondary antibody), and drained and incubated overnight in primary antibody in $0.1 \%$ BSA in PBS (CD133 (Abcam), Bmil (New England Biolabs), $\beta$ catenin (New England Biolabs) and E-cadherin (BD Biosciences)). Secondary antibodies were Alexa ${ }^{488}$-conjugated Rabbit anti-Ms or Goat anti-Rabbit Immunoglobulins (Invitrogen). Cells were washed and counterstained with DAPI (Sigma) before mounting in Permafluor (Thermo Scientific, Loughborough, UK).

\section{Clonogenicity}

Caco-2 cells were removed from flasks with Trypsin/EDTA solution and then added to an equal amount of DMEM with $10 \%$ FBS. Cells were washed twice with DMEM, and then suspended in serum-free medium (TS). Cells were filtered through a $40-\mu \mathrm{m}$ cell strainer (BD Biosciences) to remove clumps and counted. A singlecell suspension of Caco-2 cells was seeded into either BD Biocoat $6 \mathrm{~cm}$ dishes or control uncoated dishes in serum-free medium 
(TS). Cells were fed twice weekly with an $80 \%$ medium change for 5 weeks, and then fixed and stained with crystal violet. Colonies $>10$ cells were counted in the whole of each dish.

\section{RESULTS}

Type I collagen induces EMT-like changes in human colorectal cancer cell lines

HRA-19, Colony 29 and Caco-2 cells were seeded onto tissue culture plastic or type I collagen-coated dishes (BioCoat) in serumfree medium. HRA-19 and Caco-2 cells showed a more flattened less cohesive morphology on type I collagen (unpublished observations), but Colony 29 cells displayed a dramatic scattering of cells not previously described for a colon cancer cell line (Figure 1A). Type I collagen also induced a downregulation of E-cadherin at cell-cell junctions in Colony 29, Caco-2 cells and HRA-19 cells (Figure 1B) although total E-cadherin protein was not reduced (Figure 1D). Interestingly, there were substantial differences in total E-cadherin between cell lines with a much lower level of E-cadherin in Colony 29 cells, the cell line showing the most marked morphological response to type I collagen (Figure 1D and A).

$\beta$-Catenin showed strong membrane expression at cell-cell contacts in Caco-2 cells on tissue culture plastic (Figure 1C), whereas Caco-2 cells on type I collagen showed a downregulation of cell-cell $\beta$-catenin and enhanced nuclear expression (Figure 1C). Colony 29 cells showed both cell-cell and nuclear $\beta$-catenin staining on plastic but on type I collagen; $\beta$-catenin was predominantly localised in the nucleus (Figure 1C). HRA-19 cells showed a strong cell-cell $\beta$-catenin expression on tissue culture plastic, with a small reduction seen in spread cells on type I collagen (Figure 1C), and nuclear $\beta$-catenin could only be discerned in isolated cells (white arrow; Figure 1C).

As type I collagen is the preferred ligand for $\alpha 2 \beta 1$ integrin (Kapyla et al, 2000), $\alpha 2 \beta 1$ integrin expression was also analysed. Although $\alpha 2 \beta 1$ integrin expression was similar on plastic or collagen, there were marked differences between cell lines (Figure 1D). It was notable that the cell line that had the most marked response to type I collagen, Colony 29, expressed much higher levels of $\alpha 2$ integrin (Figure 1D).

\section{Type I collagen inhibits lineage differentiation in human colorectal cancer cells}

Type I collagen was shown to markedly inhibit endocrine lineage commitment in the multipotent human colorectal cancer line, HRA-19 (Figure 2A).

Type I collagen was also shown to inhibit expression of the enterocytic marker alkaline phosphatase (Matsumoto et al, 1990) in Caco-2, Colony 29 and HRA-19 cells using an enzymatic method for alkaline phosphatase assay (Figure 2B). Inhibition of enterocytic differentiation markers was confirmed by measuring intestinal alkaline phosphatase protein expression using a cellbased ELISA. Cell-based ELISA has been shown to be a sensitive assay for total (Versteeg et al, 2000) and cell surface (Hagi-Pavli et al, 2004) protein expression in intact cell monolayers. Intestinal alkaline phosphatase expression was shown to be markedly reduced in all cell lines when grown on type I collagen compared with plastic controls (Figure 2C).

\section{Type I collagen increases the expression of stem cell- associated markers CD133 and Bmil}

Recent studies have suggested that EMT is linked with the expression of a stem cell phenotype. To examine this possibility, cells undergoing EMT-like changes on type I collagen were analysed for expression of putative stem cell markers CD133 and
A

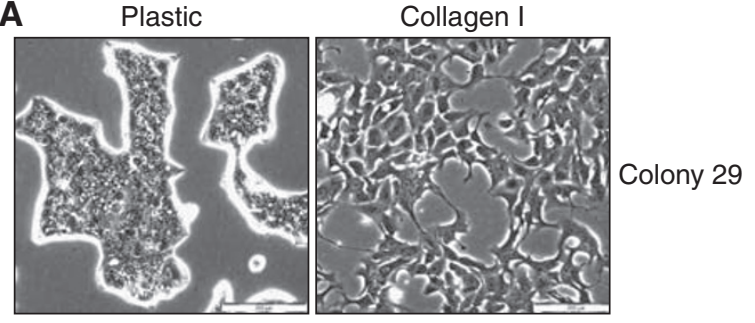

B
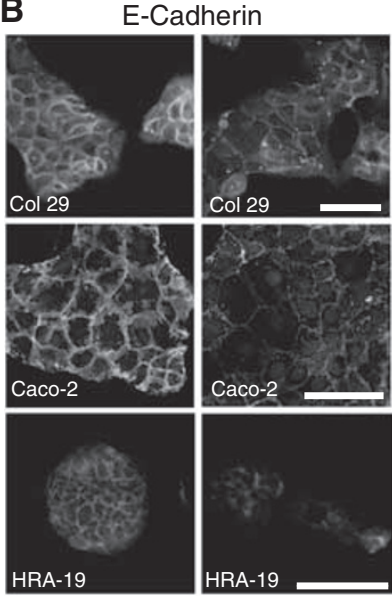

Plastic
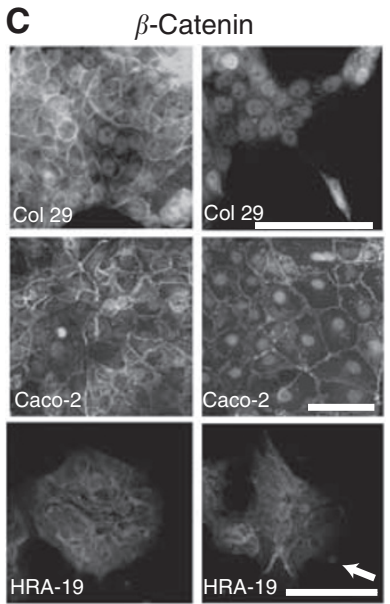

Plastic

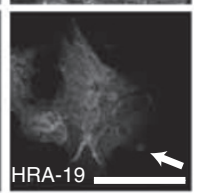

Collagen I

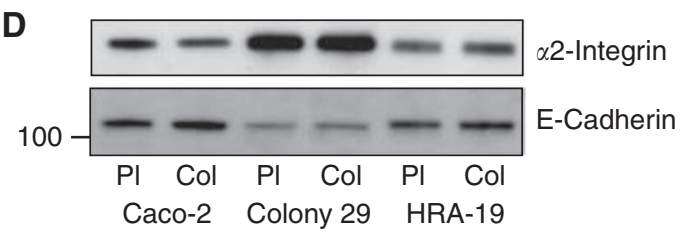

Figure I Type I collagen induces EMT-like changes in colorectal cancer cell lines. (A) Phase contrast micrographs of Colony 29 cells grown for $48 \mathrm{~h}$ in serum-free medium (IT) on plastic tissue culture dishes (plastic) or dishes coated with type | collagen (collagen I). Scale bar $=200 \mu \mathrm{m}$. (B) Immunofluorescent staining for E-cadherin expression in Colony 29 , Caco-2 and HRA-19 cells grown for $72 \mathrm{~h}$ in serum-free medium (IT) on tissue culture plastic (plastic) or collagen-coated plastic (collagen I). Cells were imaged using fluorescence microscopy. Cells were counterstained with DAPI (blue). Scale bars $=100 \mu \mathrm{m}$. (C) Immunofluorescent staining for $\beta$-catenin expression in Colony 29 , Caco-2 and HRA-19 cells grown for $72 \mathrm{~h}$ in serum-free medium (IT) on tissue culture plastic (plastic) or collagen-coated plastic (collagen I). Cells were imaged using fluorescence microscopy. White arrow in HRA- 19 collagen panel shows a single cell with nuclear $\beta$-catenin expression. Scale bars $=100 \mu \mathrm{m}$. (D) Caco-2, Colony 29 and HRA-19 cells were seeded onto tissue culture plastic (PI) or type I collagen (Col)-coated plastic and incubated at $37^{\circ} \mathrm{C}$. Lysates were prepared after $48 \mathrm{~h}$. Western blot for $\alpha 2$ integrin and E-cadherin was performed on $10 \mu \mathrm{g}$ cell lysate.

Bmil. An enhanced surface CD133 expression has been shown to characterise a sub-population of human colorectal cancer cells with tumour-initiating characteristics (O'Brien et al, 2007; RicciVitiani et al, 2007). Bmil has been shown to be a marker of adult intestinal stem cells (Sangiorgi and Capecchi, 2008).

CD133 and Bmil expression was first confirmed by immunocytochemistry. Colony 29 cells were shown to express CD133 in a sub-population of cells (Figure 3A) and Bmil was expressed by the majority of Colony 29 and HRA-19 cells (Figure 3B). Although staining appeared stronger in cells on type I collagen, the pattern of staining on plastic was indistinguishable from collagen cultures; therefore, just images from collagen cultures were used to illustrate 
A

Endocrine lineage commitment

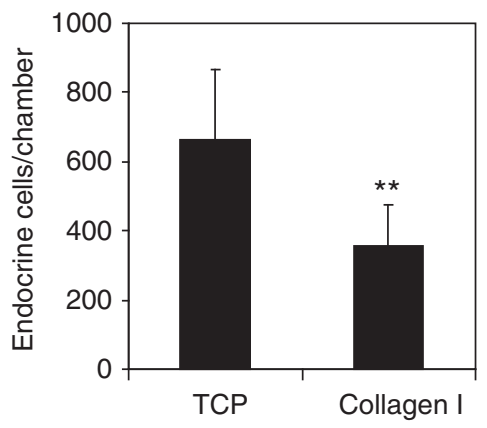

Enterocytic differentiation
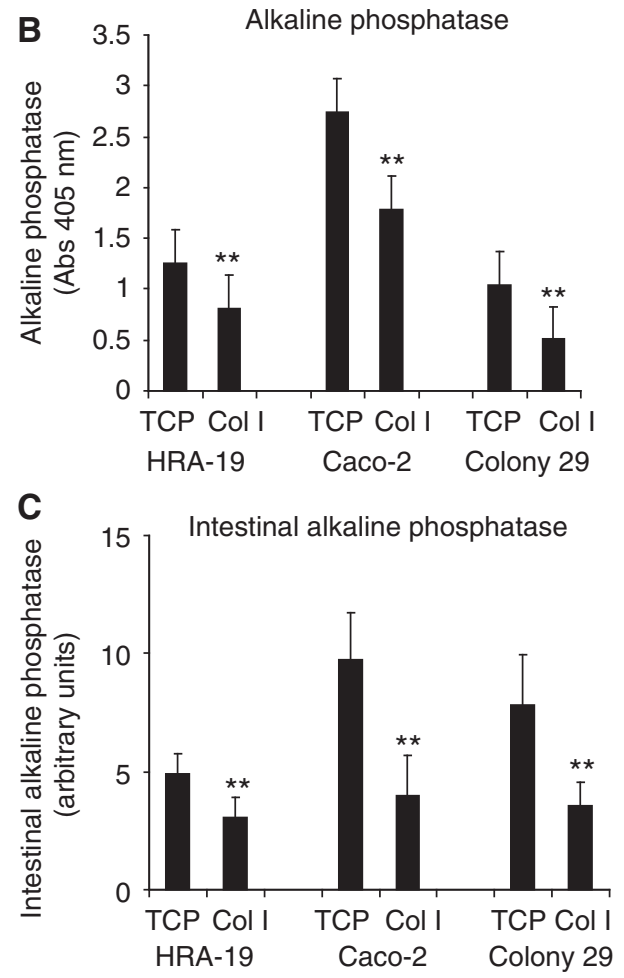

Figure 2 Collagen I inhibits lineage differentiation in human colorectal cancer cells. (A) Endocrine lineage commitment in multipotent HRA-19 cells when grown on tissue culture plastic (TCP) and type I collagen-coated plastic (collagen I). Equal numbers of cells were seeded at a I $: 5$ split ratio in eight-chamber slides, grown for $72 \mathrm{~h}$ in $10 \%$ FBS in DMEM and then transferred to serum-free medium (ITA) for $72 \mathrm{~h}$. Monolayers were stained for chromogranin using immunocytochemistry and total endocrine cells counted in each chamber. Quadruplicate chambers were used for each condition, results shown are combined values from three independent experiments; mean \pm s.d. $(n=3)$; $* * P<0.00$ I. (B) Alkaline phosphatase activity in HRA-19, Caco-2 and Colony 29 cells grown in plastic(TCP) or type I collagen (Col I)-coated 96-well plates for $72 \mathrm{~h}$ in serum-free medium (TS). Alkaline phosphatase absorbance values were normalised for cell number using the WST-I cell-proliferation reagent (Roche). The experiment was performed in triplicate. Results shown are mean \pm s.d. $(n=3)$ for three independent experiments; $* * * 0.005$. (C) Intestinal alkaline phosphatase expression in HRA-19, Caco-2 and Colony 29 cells grown in plastic (TCP) or type I collagen-coated 96 -well plates for $48 \mathrm{~h}$ in serumfree medium (TS). Intestinal alkaline phosphatase was measured using a cell-based ELISA in triplicate with cell number normalised using Cyquant assay (Invitrogen). Results shown are mean \pm s.d. $(n=3)$ for three independent experiments; $* * P<0.005$.

the expression pattern. Western blots confirmed CD133 and Bmi1 expression in HRA-19, Colony 29 and Caco-2 cells (unpublished observations).
A
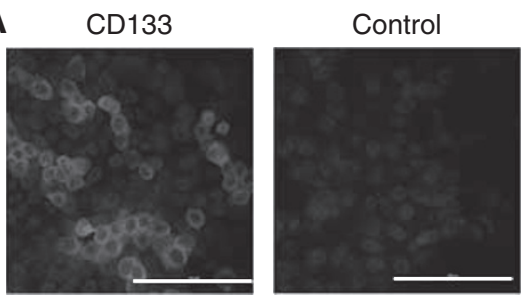

Colony 29
B Bmi1
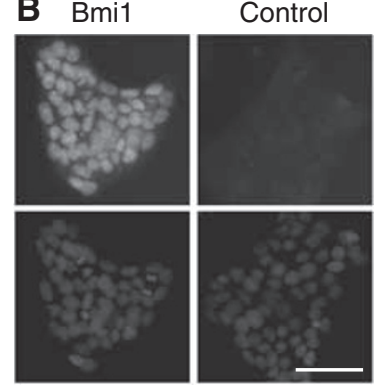

Colony 29

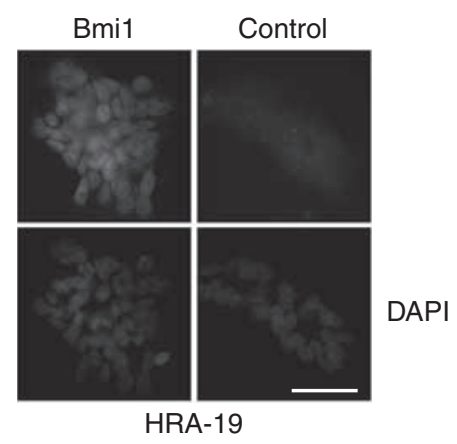

HRA-19
Figure 3 Colon cancer cell lines express stem cell-associated markers CDI33 and Bmil. (A) CDI33 expression in Colony 29 grown in serumfree medium (TS) for $48 \mathrm{~h}$. Cells were imaged using fluorescence microscopy. CDI33 (green), nuclear counterstain DAPI (blue). Control $=$ rabbit lgG control. Scale bar $=100 \mu \mathrm{m}$. (B) Bmil expression in Colony 29 cells and HRA-19 cells grown in serum-free medium (TS) for $72 \mathrm{~h}$. Cells were imaged using fluorescence microscopy. Bmil (green) nuclear counterstain DAPI (blue). Control= rabbit lgG control. Scale $\mathrm{bar}=50 \mu \mathrm{m}$.
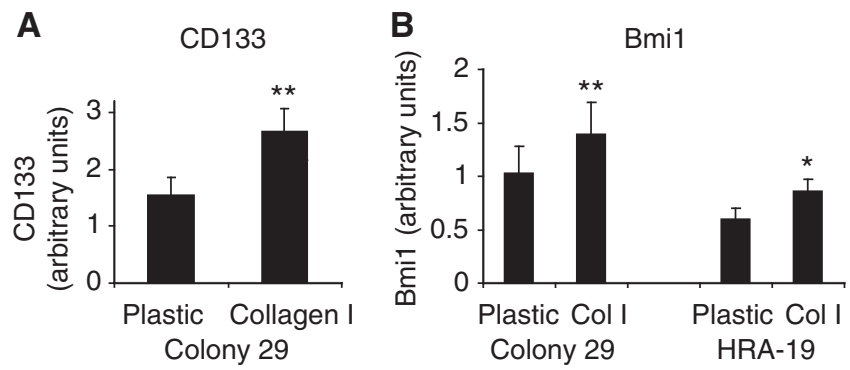

Figure 4 Type I collagen increases the expression of stem cell markers CDI33 and Bmil. (A) Cell surface expression of CDI33 in Colony 29 cells grown in serum-free medium (TS) in plastic or collagen-coated 96-well plates for $72 \mathrm{~h}$. Measurements were made in triplicate using a cell-based ELISA. Cells were fixed in $2 \%$ paraformaldehyde and not permeabilised to detect surface expression. Results presented are mean \pm s.d. of three independent experiments $(n=3)$; ** $P<0.005$. (B) Bmil expression in Colony 29 and HRA- 19 cells grown in serum-free medium (TS) in plastic or collagen-coated wells for $72 \mathrm{~h}$. Measurements were made in triplicate using a cell-based ELISA. Results presented are mean \pm s.d. of three independent experiments $(n=3)$; ** $P<0.005$; $* P<0.05$.

CD133 and Bmil expression was measured quantitatively in a cell-based ELISA on tissue culture plastic or type I collagen. The surface expression of CD133 was determined in cells following fixation in paraformaldehyde without permeabilisation. Type I collagen was shown to promote the cell surface expression of CD133 in Colony 29 cells at $72 \mathrm{~h}$ (Figure 4A). Bmil expression was also increased in HRA-19 and Colony 29 cells when grown on type I collagen compared with tissue culture plastic (Figure 4B). 

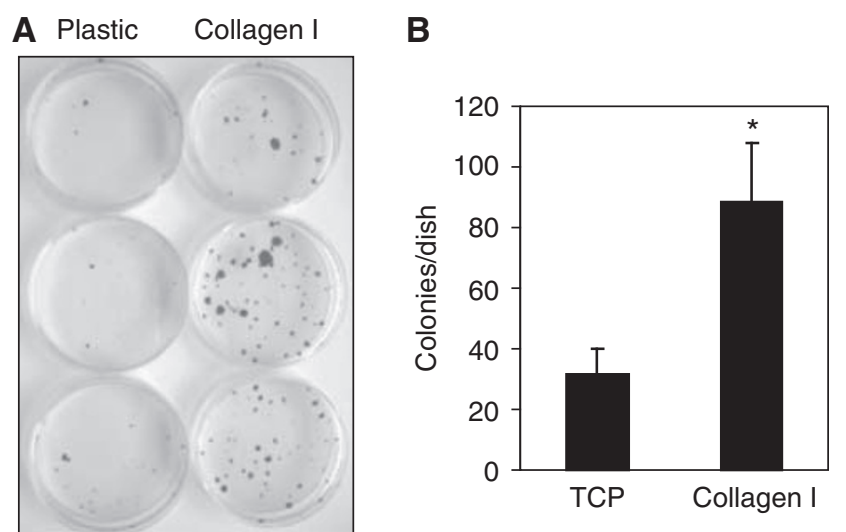

Figure 5 Collagen I increases clonogenicity in Caco-2 cells. Caco-2 cells $\left(\mid \times 10^{3}\right)$ were seeded in serum-free medium (TS) into plastic or type I collagen-coated (BioCoat) $6 \mathrm{~cm}$ dishes. Cells were fed twice weekly for 5 weeks, then fixed and stained with crystal violet. Colonies with greater than 10 cells were counted. A representative experiment shows increased colony formation on type I collagen-coated dishes $(\mathbf{A})$ and the corresponding colony counts for this experiment $(\mathbf{B})$; ${ }^{*} P<0.05$. Similar experiments were repeated four times.

\section{Type I collagen increases clonogenicity in human colorectal carcinoma cells}

The clonogenicity of cells was compared on type I collagen-coated and plastic surfaces using the Caco-2 cell line, which was the only cell line from which a single-cell suspension could be generated. Caco-2 cells showed an enhanced ability for clonal growth when seeded on a type I collagen-coated surface in serum-free medium (Figure $5 \mathrm{~A}$ and $\mathrm{B}$ ). Colonies generated on type I collagen also appeared larger than those on plastic (Figure 5A).

\section{Type I collagen effects are mediated through $\alpha 2 \beta 1$ integrin}

The interaction of colon cancer cells with collagen through $\alpha 2 \beta 1$ integrin leads to the phosphorylation of focal adhesion kinase (FAK) at $\mathrm{Tyr}^{397}$ (Sawhney et al, 2006). $\mathrm{FAK}^{397}$ was found to be more highly phosphorylated in all cell lines on type I collagen (Figure 6A), suggesting that integrin signalling was involved in the cellular responses to collagen.

To directly assess the role of $\alpha 2 \beta 1$ integrin in EMT-like phenotypic changes, Colony 29 cells were incubated with type I collagen in the presence of an $\alpha 2$ integrin function-blocking antibody, AK7, or a Ms IgG isotype control at the same concentration. Type I collagen induced a cell scattering in control cells, whereas Ak7 was shown to partially block the acquisition of this distinctive migratory phenotype in Colony 29 cells (Figure 6B). Enterocytic differentiation was also measured in cells on plastic and on type I collagen in the presence of $\alpha 2$ integrin antibody, Ak7, or Ms IgG control. Cells grown in control antibody showed the previously described reduction in differentiation on type I collagen, whereas the addition of Ak7 partially abrogated this effect (Figure 6C). These results suggest that the type I collageninduced effects on the human colorectal cancer cell phenotype are mediated, at least in part, by signalling through $\alpha 2 \beta 1$ integrin.

\section{DISCUSSION}

Transient changes in cancer cell phenotype are observed at the invasive edge of human colorectal cancers, suggesting that the microenvironment regulates tumour progression (Brabletz et al, 2001). Type I collagen is abundantly expressed at this invasive front and preliminary studies have suggested that it is responsible
A

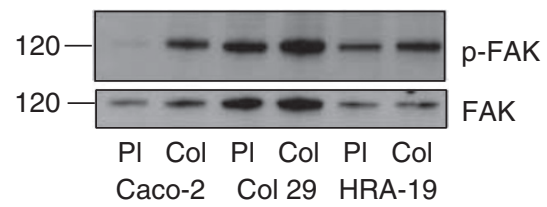

B

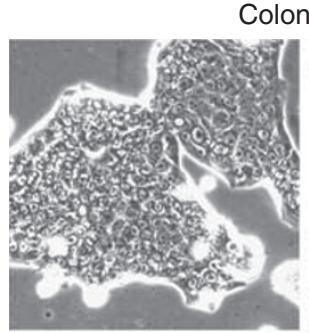

Colony 29

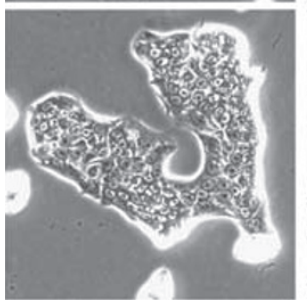

Plastic
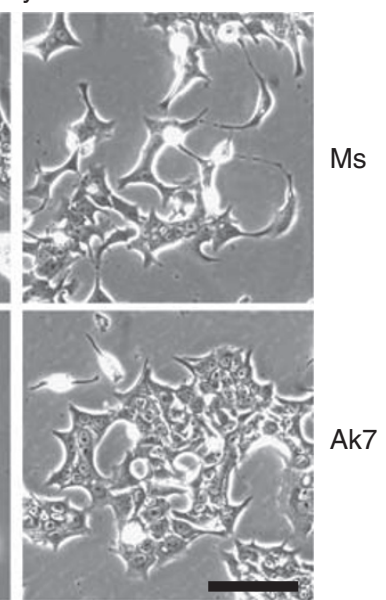

Collagen I

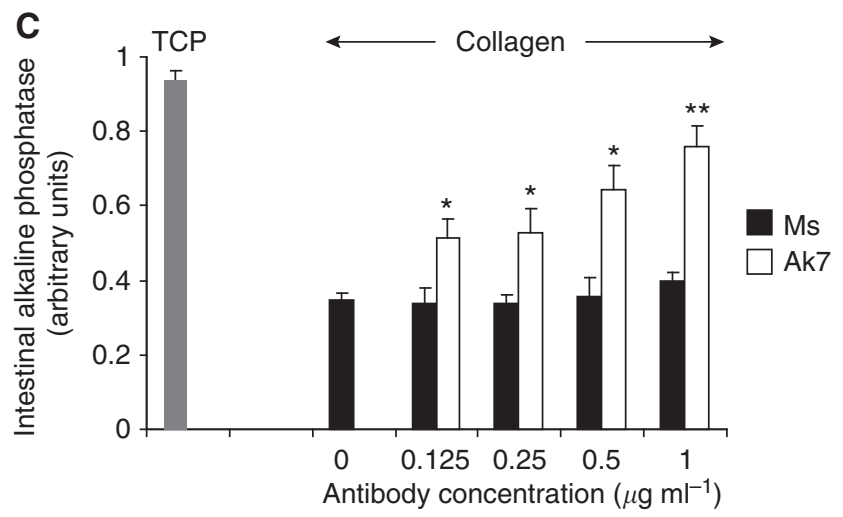

Figure 6 Collagen I effects are mediated through $\alpha 2 \beta \mid$ integrin. (A) Western blot showing total FAK and p-FAK expression in $10 \mu \mathrm{g}$ cell lysate from Caco-2, Col 29 and HRA- 19 cells after $2 \mathrm{~h}$ on tissue culture plastic (PI) or type I collagen-coated plastic (Col). (B) Phase contrast micrographs of Colony 29 cells grown in serum-free medium on tissue culture plastic (plastic) or type I collagen-coated plastic dishes for $48 \mathrm{~h}$ at $37^{\circ} \mathrm{C}$ in the presence of either Ms IgG control (Ms) or anti- $\alpha 2$ integrin (Ak7) at $300 \mathrm{ng} \mathrm{m}^{-1}$. Experiment was performed twice. Scale bar $=100 \mu \mathrm{m}$. (C) Cell-based ELISA for intestinal alkaline phosphatase activity in Colony 29 cells grown on TCP or type I collagen-coated wells (collagen) in the presence of varying concentrations of Ms IgG (Ms) or anti$\alpha 2$ integrin (Ak7). Values were normalised for cell number using WST-I reagent. Triplicate wells were used for each condition. Results shown are mean \pm s.d. $* * P<0.005$; $* P<0.05$. Other experiments with individual concentrations of antibody were performed at least three times with similar results.

for the loss of differentiation and EMT-like changes seen in this area (Brabletz et al, 2004). This study confirms and extends these findings, showing that human colorectal carcinoma cell lines undergo the initial steps of EMT when plated onto type I collagen. These EMT-like changes include a spectrum of morphological changes between cell lines ranging from a more flattened and less cohesive morphology to the dramatic scattered morphology seen in Colony 29. Further evidence of EMT-like changes on type I collagen was provided by the downregulation of E-cadherin at 
cell-cell junctions as shown previously in pancreatic carcinoma cells (Grzesiak et al, 2005; Koenig et al, 2006). In pancreatic carcinoma cells, some studies show an additional decrease in E-cadherin protein on type I collagen (Koenig et al, 2006). In this study, the downregulation of E-cadherin at cell-cell junctions was not accompanied by a decrease in E-cadherin protein expression in agreement with other studies on pancreatic carcinoma cells (Shintani et al, 2006). However, constitutive levels of E-cadherin were shown to be much lower in Colony 29 cells than in Caco-2 or HRA-19, raising the possibility that this inherent characteristic rendered the cells more responsive to type I collagen. Some evidence to support this notion comes from work on the HCA-7 cell line, the parent line of Colony 29 cells, which also shows a low level of E-cadherin protein expression (Chang et al, 2006). In HCA-7 cells, E-cadherin is downregulated by constitutive expression of COX-2 and RhoA, which are associated with the disruption of adherens junctions in these cells (Chang et al, 2006). COX-2-dependent pathways upregulate ZEB1 and Snail, transcriptional suppressors of E-cadherin in lung cancer cells (Dohadwala et al, 2006). ZEB1 represses differentiation and cell-cell adhesion in human colorectal carcinoma cells (Aigner et $a l, 2007)$. In addition, a stable COX-2 expression in breast epithelial cells enhances EMT (Neil et al, 2008). Therefore, it seems likely that the elevated levels of COX-2 in Colony 29 cells (Chinery et al, 1999) are involved in enhancing the response of these cells to type I collagen.

$\beta$-Catenin has dual functions in cell-cell adhesion and transcription, with an imbalance between these two functions leading to cancer formation (Harris and Peifer, 2005). Nuclear $\beta$-catenin, an indicator of active Wnt signalling, acts as a transcriptional activator in concert with TCF proteins and is both important in normal stem cell renewal and the main oncoprotein in human colorectal cancer (Peifer, 1997). The exposure of Colony 29 and Caco- 2 cells to type I collagen resulted in a loss of $\beta$-catenin at cell-cell contacts and an increase in nuclear $\beta$-catenin. Nuclear $\beta$-catenin is observed in the invasive cells of human colorectal cancer (Brabletz et al, 2001), suggesting that the exposure of cancer cells to type I collagen at the invasive edge enhances nuclear $\beta$ catenin expression. Nuclear $\beta$-catenin has been shown to impose an undifferentiated progenitor phenotype on colorectal cancer cells (van de Wetering et al, 2002); therefore, the differentiation and expression of stem cell characteristics were compared between cells growing on plastic and type I collagen.

Type I collagen has previously been shown to reduce $\mathrm{cdx}-2$ expression in colon cancer cells (Brabletz et al, 2004). This study confirms and extends this earlier study by showing that type I collagen inhibits enterocytic differentiation in all cell lines tested. The study was extended to compare cell fate decisions by multipotent colorectal cancer cells (HRA-19) when grown on tissue culture plastic and type I collagen. Endocrine lineage commitment was inhibited by the growth of cells on type I collagen, suggesting that type I collagen promotes self-renewal, maintaining colorectal carcinoma cells in an undifferentiated progenitor state.

This study shows that type I collagen induces EMT-like changes and a loss of differentiation in human colorectal carcinoma cells. Interestingly, recent studies have linked EMT with the acquisition of stem cell properties in mammary epithelial cells (Mani et al, 2008). Therefore, stem cell marker expression was investigated to determine whether the EMT-like changes observed on collagen were similarly associated with a stem cell-like phenotype. Two stem cell markers, CD133 and Bmi1, were chosen and Colony 29 cells investigated in greater detail as they displayed the greatest EMT-like response to type I collagen. Cell surface CD133 has been shown to be a stem cell marker in normal and neoplastic cells (Mizrak et al, 2008), including human colorectal cancer stem cells (O'Brien et al, 2007; Ricci-Vitiani et al, 2007).Cell surface expression of CD133 was increased on Colony 29 cells grown on type I collagen, suggesting that type I collagen maintains the stem cell phenotype. Further evidence for this was sought using another stem cell marker, Bmil, which has a role in self-renewal in a variety of stem cells and has recently been shown to be an intestinal stem cell marker (Sangiorgi and Capecchi, 2008) . Colony 29 cells also showed increased Bmil expression when grown on type I collagen, further supporting the idea that cells were expressing a more stem cell-like phenotype. Increased Bmil expression was also observed in HRA-19 cells on type I collagen. Bmil is involved in self-renewal in haematopoietic and neuronal cells (Lessard and Sauvageau, 2003; Molofsky et al, 2003). In addition, Bmil expression is dysregulated in preneoplastic colorectal epithelium and overexpression correlates with malignant progression (Tateishi et al, 2006), supporting a role for Bmil in human colorectal cancer progression. Previous studies have shown that HRA-19 cells, which have a low inherent tumourigenicity, acquired a $100 \%$ take rate in xenografts when embedded in type I collagen gel (Del-Buono et al, 1991), suggesting a functional significance to colon cancer cell-collagen interactions. To examine whether an increased expression of stem cell markers was accompanied by any functional attributes of stem cells, clonogenicity on type I collagen was determined. Clonogenicity is associated with the stem cell phenotype and was enhanced in Caco-2 cells when grown on type I collagen.

We have recently shown that $\alpha 2 \beta 1$ integrin regulates cell fate decisions in the multipotent colorectal cancer cell line, HRA-19 (Kirkland and Ying, 2008).This study provides evidence that $\alpha 2 \beta 1$ integrin is involved in type I collagen-induced EMT-like changes and loss of differentiation. However, Ak7, an $\alpha 2$ function-blocking antibody, was only able to partially abrogate type I collageninduced effects on colon cancer cell phenotype, suggesting the possible involvement of other collagen receptors. For example, it has been shown recently that $\alpha 2 \beta 1$ integrin cooperates with Discoidin domain receptor I, a tyrosine kinase collagen receptor, to increase $\mathrm{N}$-cadherin expression in pancreatic cancer cells (Shintani et al, 2008).

In this study, the interaction between colon cancer cells and type I collagen results in EMT-like changes, a loss of differentiation and an increased expression of stem cell markers. These phenotypic changes are all characteristics of cancer cells at the invasive edge of human colorectal cancers. The link between EMT-like changes and expression of a stem cell phenotype supports the concept of a migrating cancer stem cell being involved in tumour progression and dissemination (Brabletz et al, 2005). Overall, the results indicate that type I collagen promotes the expression of a more malignant, stem cell-like phenotype in human colorectal cancer cells.

\section{ACKNOWLEDGEMENTS}

This work was supported by grant 060688 from The Wellcome Trust. I am grateful to Professor G Stamp for the support provided.

\section{REFERENCES}

Aigner K, Dampier B, Descovich L, Mikula M, Sultan A, Schreiber M, Mikulits W, Brabletz T, Strand D, Obrist P, Sommergruber W, Schweifer
N, Wernitznig A, Beug H, Foisner R, Eger A (2007) The transcription factor ZEB1 ([delta]EF1) promotes tumour cell dedifferentiation by 
repressing master regulators of epithelial polarity. Oncogene 26: 69796988

Brabletz T, Jung A, Reu S, Porzner M, Hlubek F, Kunz-Schughart LA Knuechel R, Kirchner T (2001) Variable beta -catenin expression in colorectal cancers indicates tumor progression driven by the tumor environment. Proc Natl Acad Sci USA 98: 10356-10361

Brabletz T, Jung A, Spaderna S, Hlubek F, Kirchner T (2005) Migrating cancer stem cells - - an integrated concept of malignant tumour progression. Nat Rev Cancer 5: 744-749

Brabletz T, Spaderna S, Kolb J, Hlubek F, Faller G, Bruns CJ, Jung A, Nentwich J, Duluc I, Domon-Dell C, Kirchner T, Freund J-N (2004) Down-regulation of the homeodomain factor $\mathrm{Cdx} 2$ in colorectal cancer by collagen type I: an active role for the tumor environment in malignant tumor progression. Cancer Res 64: 6973-6977

Brittan M, Wright NA (2004) Stem cell in gastrointestinal structure and neoplastic development. Gut 53: 899-910

Chang Y-WE, Marlin JW, Chance TW, Jakobi R (2006) RhoA mediates cyclooxygenase-2 signaling to disrupt the Formation of adherens junctions and increase cell motility. Cancer Res 66: 11700-11708

Chinery R, Coffey RJ, Graves-Deal R, Kirkland SC, Sanchez SC, Zackert WE, Oates JA, Morrow JD (1999) Prostaglandin J2 and 15-deoxy-\{\{Delta)\}12,14-prostaglandin J2 induce proliferation of cyclooxygenasedepleted colorectal cancer cells. Cancer Res 59: 2739-2746

Dalerba P, Dylla SJ, Park I-K, Liu R, Wang X, Cho RW, Hoey T, Gurney A, Huang EH, Simeone DM, Shelton AA, Parmiani G, Castelli C, Clarke MF (2007) Phenotypic characterization of human colorectal cancer stem cells. Proc Natl Acad Sci USA 104: 10158-10163

Del-Buono R, Pignatelli M, Hall P (1991) Control of differentiation in a rectal adenocarcinoma cell line: the role of diffusable and cell associated factors. J Pathol 164: 59-66

Dohadwala M, Yang S-C, Luo J, Sharma S, Batra RK, Huang M, Lin Y, Goodglick L, Krysan K, Fishbein MC, Hong L, Lai C, Cameron RB, Gemmill RM, Drabkin HA, Dubinett SM (2006) Cyclooxygenase-2dependent regulation of E-cadherin: prostaglandin E2 induces transcriptional repressors ZEB1 and snail in non-small cell lung cancer. Cancer Res 66: $5338-5345$

Gamble J, Matthias L, Meyer G, Kaur P, Russ G, Faull R, Berndt M, Vadas M (1993) Regulation of in vitro capillary tube formation by anti-integrin antibodies. J Cell Biol 121: 931 - 943

Grzesiak J, Bouvet M (2006) The $\alpha 2 \beta 1$ integrin mediates the malignant phenotype on type I collagen in pancreatic cancer cell lines. Br J Cancer 94: $1311-1319$

Grzesiak J, Smith K, Chalberg C, Burton D, Deftos L, Bouvet M (2005) Type I collagen and divalent cation shifts disrupt cell-cell adhesion, increase migration, and decrease PTHrP, IL-6, and IL-8 expression in pancreatic cancer cells. Int J Gastrointest Cancer 36: 131 - 146

Hagi-Pavli E, Farthing P, Kapas S (2004) Stimulation of adhesion molecule expression in human endothelial cells (HUVEC) by adrenomedullin and corticotrophin. Am J Physiol Cell Physiol 286: C239-C246

Harris TJC, Peifer M (2005) Decisions, decisions: [beta]-catenin chooses between adhesion and transcription. Trends Cell Biol 15: 234-237

Ho S, Itzkowitz S, AM F, Jiang S, Kim Y (1989) Cell lineage markers in premalignant and malignant colonic mucosa. Gastroenterology 97: $392-404$

Kapyla J, Ivaska J, Riikonen R, Nykvist P, Pentikainen O, Johnson M, Heino $\mathrm{J}$ (2000) Integrin alpha 2I domain recognizes type I and type IV collagens by different mechanisms. J Biol Chem 275: 3348-3354

Kirkland S (1988) Clonal origin of columnar, mucous and endocrine cell lineages in human colorectal epithelium. Cancer 61: 1359-1363

Kirkland SC, Henderson K (2001) Collagen IV synthesis is restricted to the enteroendocrine pathway during multilineage differentiation of human colorectal epithelial stem cells. J Cell Sci 114: 2055 - 2064

Kirkland SC, Ying H (2008) \{alpha\}2\{beta\}1 integrin regulates lineage commitment in multipotent human colorectal cancer cells. J Biol Chem 283: $27612-27619$

Klymkowsky M, Savagner P (2009) Epithelial-mesenchymal transition: a cancer researcher's conceptual friend or foe. Am J Pathol 174: $1588-1593$

Koenig A, Mueller C, Hasel C, Adler G, Menke A (2006) Collagen type I induces disruption of E-cadherin-mediated cell-cell contacts and promotes proliferation of pancreatic carcinoma cells. Cancer Res 66: $4662-4671$

Lessard J, Sauvageau G (2003) Bmi-1 determines the proliferative capacity of normal and leukaemic stem cells. Nature 423: 255-260
Mani SA, Guo W, Liao M-J, Eaton EN, Ayyanan A, Zhou AY, Brooks M, Reinhard F, Zhang CC, Shipitsin M, Campbell LL, Polyak K, Brisken C, Yang J, Weinberg RA (2008) The epithelial-mesenchymal transition generates cells with properties of stem cells. Cell 133: 704-715

Marsh K, Stamp G, Kirkland S (1993) Isolation and characterization of multiple cell types from a single human colonic carcinoma: tumourigenicity of these cell types in a xenograft system. J Pathol 170: 441-450

Matsumoto H, Erickson R, Gum J, Yoshioka M, Gum E, Kim Y (1990) Biosynthesis of alkaline phosphatase during differentiation of the human colon cancer cell line Caco-2. Gastroenterology 98: 1199-1207

Mizrak D, Brittan M, Alison MR (2008) CD133: molecule of the moment. J Pathol 214: 3 -9

Molofsky AV, Pardal R, Iwashita T, Park I-K, Clarke MF, Morrison SJ (2003) Bmi-1 dependence distinguishes neural stem cell self-renewal from progenitor proliferation. Nature 425: $962-967$

Neil JR, Johnson KM, Nemenoff RA, Schiemann WP (2008) Cox-2 inactivates Smad signaling and enhances EMT stimulated by TGF-\{beta\} through a PGE2-dependent mechanisms. Carcinogenesis 29: 2227-2235

O'Brien CA, Pollett A, Gallinger S, Dick JE (2007) A human colon cancer cell capable of initiating tumour growth in immunodeficient mice. Nature 445: $106-110$

Oku Y, Shimoji T, Takifuji K, Hotta T, Yokoyama S, Matsuda K, Higashiguchi T, Tominaga T, Nasu T, Tamura K, Matsuura M, Miyata S, Kato Y, Yamaue H, Miki Y (2008) Identification of the molecular mechanisms for dedifferentiation at the invasion front of colorectal cancer by a gene expression analysis. Clin Cancer Res 14: 7215-7222

Peifer M (1997) Beta-catenin as oncogene-the smoking gun. 10.1126/ science.275.5307.1752. Science 275: 1752 - 1753

Ramaswamy S, Ross KN, Lander ES, Golub TR (2003) A molecular signature of metastasis in primary solid tumors. 33: 49-54

Reya T, Clevers H (2005) Wnt signalling in stem cells and cancer. Nature 434: $843-850$

Ricci-Vitiani L, Lombardi DG, Pilozzi E, Biffoni M, Todaro M, Peschle C, De Maria R (2007) Identification and expansion of human colon-cancerinitiating cells. Nature 445: $111-115$

Sangiorgi E, Capecchi MR (2008) Bmil is expressed in vivo in intestinal stem cells. Nat Genet 40: $915-920$

Sawhney RS, Cookson MM, Omar Y, Hauser J, Brattain MG (2006) Integrin $\backslash$ \{alpha $\} 2$-mediated ERK and calpain activation play a critical role. J Biol Chem 281: $8497-8510$

Shintani Y, Fukumoto Y, Chaika N, Svoboda R, Wheelock MJ, Johnson KR (2008) Collagen I-mediated up-regulation of $\mathrm{N}$-cadherin requires cooperative signals from integrins and discoidin domain receptor 1 . J Cell Biol 180: 1277-1289

Shintani Y, Hollingsworth MA, Wheelock MJ, Johnson KR (2006) Collagen I promotes metastasis in pancreatic cancer by activating c-Jun $\mathrm{NH} 2$ terminal kinase 1 and up-regulating $\mathrm{N}$-cadherin expression. Cancer Res 66: $11745-11753$

Spaderna S, Schmalhofer O, Hlubek F, Berx G, Eger A, Merkel S, Jung A, Kirchner T, Brabletz T (2006) A transient, EMT-linked loss of basement membranes indicates metastasis and poor survival in colorectal cancer. Gastroenterology 131: $830-840$

Tateishi K, Ohta M, Kanai F, Guleng B, Tanaka Y, Asaoka Y, Tada M, Seto M, Jazag A, Lianjie L, Okamoto M, Isayama H, Tada M, Yoshida H, Kawabe T, Omata M (2006) Dysregulated expression of stem cell factor Bmil in precancerous lesions of the gastrointestinal tract. Clin Cancer Res 12: 6960-6966

Thiery JP, Sleeman JP (2006) Complex networks orchestrate epithelial mesenchymal transitions. Nat Rev Mol Cell Biol 7: 131-142

van de Wetering M, Sancho E, Verweij C, de Lau W, Oving I, Hurlstone A, van der Horn K, Batlle E, Coudreuse D, Haramis A-P, Tjon-Pon-Fong M, Moerer P, van den Born M, Soete G, Pals S, Eilers M, Medema R, Clevers $\mathrm{H}$ (2002) The [beta]-Catenin/TCF-4 complex imposes a crypt progenitor phenotype on colorectal cancer cells. Cell 111: $241-250$

Vermeulen L, Todaro M, de Sousa Mello F, Sprick MR, Kemper K, Perez Alea M, Richel DJ, Stassi G, Medema JP (2008) Single-cell cloning of colon cancer stem cells reveals a multi-lineage differentiation capacity. Proc Natl Acad Sci USA 105: $13427-13432$

Versteeg H, Nijhuis E, Brink GVD, Evertzen M, Pynaert G, Deventer SV, Coffer P, Peppelenbosch M (2000) A new phosphospecific cell-based ELISA for p42/p44 mitogen-activated protein kinase (MAPK), p38 MAPK, protein kinase B and cAMP-response-element-binding protein. Biochem J 350: 717-722 